\title{
HAK UNTUK MENDAPATKAN PEGUAM SEMASA PERBICARAAN JENAYAH BAGI GOLONGAN YANG TIDAK BERKEMAMPUAN DI MALAYSIA ${ }^{1}$
}

\author{
Zulazhar bin Tahir \\ Universiti Malaya, Kuala Lumpur
}

\begin{abstract}
Abstrak
Hak untuk mendapatkan peguam terutama dalam kes-kes jenayah adalah amat penting. Hak ini sebenarnya telah diperuntukkan di bawah Artikel 5(3) Perlembagaan Persekutuan. Malahan seksyen 255 Kanun Prosedur Jenayah turut memperuntukkan hak untuk dibela oleh seorang peguam bagi tertuduh yang sedang dibicarakan di Mahkamah. Seksyen 28A Kanun Prosedur Jenayah juga turut memperuntukkan hak untuk mendapatkan peguam ini bagi seseorang yang ditangkap. Selain daripada itu, bantuan guaman bagi mereka yang tidak berkemampuan turut diberikan oleh Jabatan Bantuan Guaman melalui Akta Bantuan Guaman 1971. Di samping itu, bantuan gumanan ini juga turut diberikan oleh Majlis Peguam bagi membantu golongan-golongan yang tidak berkemampuan ini. Namun begitu, persoalan yang timbul ialah adakah bantuan ini mencapai sasarannya iaitu untuk membantu golongan yang tidak berkemampuan dalam mendapatkan khidmat seorang peguam di Malaysia? Selain itu, persoalan yang seterusnya ialah adakah bantuan yang diberikan mencukupi dalam memberikan keadilan kepada golongan yang tidak berkemampuan ini? Persoalan ini penting untuk dijawab memandangkan ketidakhadiran peguam untuk membantu seseorang tertuduh semasa perbicaraan mengibaratkan kedudukan tertuduh seperti telur dihujung tanduk. Malah tertuduh juga akan menghadapi risiko yang amat tinggi untuk disabitkan jika tidak dibantu oleh seorang peguam semasa perbicaraan. Oleh itu, artikel ini akan mengupas kepentingan dan keberkesanan hak untuk mendapatkan peguam ini dalam membantu golongan yang miskin di Malaysia. Selain itu, artikel ini juga akan membuat perbandingan dengan beberapa negara Komenwel yang lain dalam melihat keberkesanan hak untuk mendapatkan peguam dalam membantu golongan yang tidak berkemampuan di negara-negara mereka.
\end{abstract}

1 Artikel ini telah dibentangkan oleh penulis di Persidangan Kebangsaan Sains Sosial Unimas 2011: Pembangunan ke Arah Masa Depan yang Mapan, 20-21 April 2011, CTF1 Kampus Barat, Universiti Malaysia Sarawak. 


\section{Pengenalan}

Apakah yang dimaksudkan dengan kemiskinan? Siapakah yang dikategorikan sebagai miskin? Definisi kemiskinan terbahagi kepada tiga iaitu keluarga miskin tegar yang berpendapatan RM440 ke bawah, keluarga miskin yang berpendapatan RM750 ke bawah dan keluarga berpendapatan rendah iaitu RM2000 ke bawah. ${ }^{2}$ Setakat ini, terdapat 49,413 keluarga amat miskin, 68,033 keluarga miskin dan 2.1 juta keluarga yang berpendapatan rendah di Malaysia. ${ }^{3}$ Statistik ini menunjukkan bahawa bilangan keluarga berpendapatan rendah dan miskin di Malaysia adalah besar jumlahnya. Oleh itu, golongan ini memerlukan bantuan agar mereka dapat menikmati secara saksama nikmat kekayaan dan kemakmuran yang ada di Malaysia. Salah satu daripada nikmat tersebut adalah hak untuk mendapatkan peguam sebagaimana yang telah dijamin oleh Perlembagaan Persekutuan. Namun begitu, persoalannya ialah adakah hak untuk mendapatkan peguam ini mampu dinikmati oleh golongan yang tidak berkemampuan ini? Ini kerana walaupun akses kepada peguam merupakan suatu hak namun ia bukanlah sesuatu yang percuma. Hak ini adakalanya dianggap hak yang hanya mampu dinikmati oleh golongan kaya sahaja kerana jumlah kos bagi sesuatu kes jenayah adalah tinggi dan ada ketikanya boleh mencapai sehingga ratusan ribu ringgit. Justeru itu, wujudkah peluang untuk golongan yang tidak berkemampuan ini untuk turut sama menikmati hak ini di Malaysia? Perkara ini akan dapat dilihat berdasarkan kepada undang-undang serta sistem bantuan yang telah diwujudkan sama ada oleh pihak kerajaan mahupun swasta di Malaysia.

\section{Kepentingan Hak Untuk Mendapatkan Peguam}

Dalam sesuatu perbicaraan jenayah, adalah penting untuk memberikan seseorang tertuduh kebebasan untuk menghujahkan kesnya dengan sebaik mungkin. ${ }^{4}$ Ini kerana, isu sama ada beliau akan disabitkan atau tidak bergantung kepada keterangan yang dikemukakan semasa perbicaraan. Namun begitu, sesuatu

2 Datuk Seri Shahrizat Abdul Jalil Menteri di Kementerian Pembangunan Wanita dan Masyarakat, http://bernama.com/bernama/vs/bm/newsindex.php? id.463267- Akses pada 19 Januari 2010.

3 Ibid.

4 Kes Goldberg v. Kelly [1970] 397 U.S. 254. 
perbicaraan adalah begitu kompleks dan hanya mereka yang terlatih sahaja dapat mengendalikan situasi perbicaraan tersebut dengan baik. Oleh yang demikian, seseorang tertuduh yang tidak mempunyai kepakaran tersebut perlu dibantu agar beliau dapat mengendalikan kesnya semasa perbicaraan. ${ }^{5}$ Selain itu, tertuduh juga terpaksa berhadapan dengan pihak pendakwaan yang mempunyai pelbagai sumber dan kebolehan untuk menyabitkannya. Dalam keadaan ini, seseorang tertuduh yang tidak diwakili oleh seorang peguam mungkin berhadapan dengan risiko sabitan yang tinggi dan menyebabkan ketidakadilan kepada tertuduh. ${ }^{6}$ Keperluan ini akan lebih mendesak apabila tertuduh tersebut didakwa dengan kesalahan yang boleh membawa hukuman mati atau penjara seumur hidup. ${ }^{7}$ Dalam keadaan-keadaan di atas, peguam mempunyai peranan yang penting dalam membantu tertuduh untuk mengendalikan kesnya dengan baik di mahkamah. ${ }^{8}$

Justeru itu, apabila tertuduh dibicarakan tanpa kehadiran seorang peguam maka kedudukan beliau boleh diibaratkan seperti telur di hujung tanduk. Jika perkara ini berlaku maka seseorang yang tidak bersalah mungkin boleh disabitkan di atas kesalahan yang tidak beliau lakukan. ${ }^{9}$ Oleh yang demikian, jika perkara ini dibiarkan tanpa sebarang bentuk perlindungan maka konsep keadilan tidak akan dapat dicapai. ${ }^{10}$ Malah individu-individu ini akan merasakan diri mereka teraniaya dan tidak dapat menegakkan keadilan ke atas diri mereka sendiri walaupun di mahkamah. Perkara ini ditegaskan oleh Mahkamah Agung Amerika Syarikat dalam kes Powell v. State of Alabama $^{11}$ seperti berikut;

5 Peruntukan berkenaan hak untuk diwakili oleh peguam boleh dilihat dalam Seksyen 257 Kanun Prosedur Jenayah.

6 Tapash Gan Choudhury, Penumbra of Natural Justice, $2^{\text {nd }}$ Edition, (2001) New Delhi : Eastern Law House, di muka surat 210.

7 Sebagai contohnya jika tertuduh itu dituduh di bawah seksyen 300 Kanun Keseksaan yang boleh membawa hukuman mati di bawah seksyen 302 Kanun Keseksaan.

8 Kes Pett v. Grayhound Racing Association Ltd. [1986] 2 W.L.R. 1471.

9 Mahkamah Rayuan di dalam kes Khoon Chye Hin v. Public Prosecutor [1961] 1 M.L.J. 105, membincangkan maxim undang-undang Inggeris berdasarkan kepada common law yang menjelaskan bahawa adalah lebih baik melepaskan sepuluh orang yang bersalah daripada menyabitkan seorang individu yang tidak bersalah.

10 Pellock, Seton, Legal Aid - The First 25 years, London : Oyez Publishing Limited (1975) di muka surat 5.

11287 U.S. 45 [1932]. 
What, then, does a hearing include? Historically and in practice, in our own country at least, it has always included the right to the aid of counsel when desired and provided by the party asserting the right. The right to be heard would be, in many cases, of little avail if it did not comprehend the right to be heard by counsel. Even the intelligent and educated layman has small and sometimes no skill in the science of law. If charged with crime, he is incapable, generally, of determining for himself whether the indictment is good or bad. He is unfamiliar with the rules of evidence. Left without the aid of counsel he may be put on trial without a proper charge, and convicted upon incompetent evidence, or evidence irrelevant to the issue or otherwise inadmissible. He lacks both the skill and knowledge adequately to prepare his defense, even though he had a perfect one. He requires the guiding hand of counsel at every step in the proceedings against him. Without it, though he be not guilty, he faces the danger of conviction because he does not know how to establish his innocence. If that be true of men of intelligence, how much more true is it of the ignorant and illiterate, or those of feeble intellect. If in any case, civil or criminal, a state or federal court were arbitrarily to refuse to hear a party by counsel, employed by and appearing for him, it reasonably may not be doubted that such a refusal would be a denial of a hearing, and, therefore, of due process in the constitutional sense. ${ }^{12}$

Dalam hal ini, hak untuk mendapatkan peguam turut merangkumi hak untuk dibela oleh seorang peguam yang kompeten. ${ }^{13}$ Ini kerana seorang peguam yang tidak kompeten boleh menyebabkan berlakunya ketidakadilan kepada tertuduh, ${ }^{14}$ contohnya tertuduh

12 Ibid. Kes ini juga telah dirujuk dan dipersetujui di dalam kes Shores v. United States [1935] U.S. App. LEXIS 3424.

13 Keputusan Mahkamah Persekutuan dalam kes Shamim Reza Abdul Samadv. $P P$ [2009] C.L.J. 5.

14 Sankar v. State [1994] U.K.P.C. 1. 
tidak akan mendapat pembelaan yang baik. ${ }^{15}$ Oleh itu, jika perkara ini berlaku maka hak seseorang tertuduh untuk mendapatkan suatu perbicaran yang adil akan dicabuli. ${ }^{16}$ Dalam keadaan ini, mahkamah mempunyai kuasa untuk membatalkan sabitan yang telah dikenakan ke atas seseorang tertuduh jika jelas menunjukkan bahawa peguam tertuduh tidak kompeten. ${ }^{17}$ Oleh yang demikian, mahkamah mempunyai tanggungjawab untuk menilai peranan peguam yang mewakili tertuduh agar keadilan dapat dicapai. ${ }^{18}$ Dalam erti kata lain, kehadiran seorang peguam yang kompeten dapat memastikan sesuatu perbicaraan tersebut berjalan dengan adil dan saksama.

\section{Kedudukan di Malaysia}

Di Malaysia, hak untuk mendapatkan khidmat seorang peguam merupakan sesuatu yang telah dijamin di bawah Artikel 5(3) Perlembagaan Persekutuan. Malahan seksyen 255 Kanun Prosedur Jenayah (selepas ini dirujuk sebagai KPJ) turut memberikan hak untuk dibela kepada seseorang individu yang didakwa dalam perbicaraan jenayah. ${ }^{19}$ Justeru itu, seseorang tertuduh yang sedang dibicarakan di mahkamah harus diberikan akses kepada hak ini. Perkara ini menjadi lebih penting dalam keadaan seseorang tertuduh tidak mempunyai kemampuan untuk melantik peguam bagi mewakilinya. ${ }^{20}$ Tun Mohamed Dzaiddin Hj Abdullah, ${ }^{21}$ menyatakan bahawa:

15 Pertubuhan Bangsa-Bangsa Bersatu turut mengakui kepentingan hak tertuduh untuk mendapatkan peguam yang kompeten ini dengan mengeluarkan suatu prinsip yang dikenali sebagai Basic Principles on the Role of Lawyers. Prinsip ini telah diwujudkan pada persidangan Pertubuhan Bangsa-Bangsa Bersatu yang Ke-Lapan mengenai Prevention of Crime and the Treatment of Offenders, yang telah diadakan di Havana, Cuba, pada 27 Ogos sehingga 7 September 1990. Prinsip 6 Basic Principles on the Role of Lawyers menyebut;

Any such persons who do not have a lawyer shall, in all cases in which the interests of justice so require, be entitled to have a lawyer of experience and competence commensurate with the nature of the offence assigned to them in order to provide effective legal assistance, without payment by them if they lack sufficient means to pay for such services.

16 Public Prosecutor v. Choo Chuan Wang [1992] 2 C.L.J. 1242.

17 Shamim Reza Abdul Samad v. PP [2009] C.L.J. 5.

18 Wong Lai Fatt v. Public Prosecutor [1973] 1 L.N.S. 175.

19 Zulazhar bin Tahir, Sistem Keadilan Jenayah di Malaysia : Suatu Analisis Dari Perspektif Hak-Hak Tertuduh, Fakulti Undang-Undang, Universiti Malaya, Kuala Lumpur, $\mathrm{PhD}$ (2011).

20 Ibid

21 Bekas Ketua Hakim Negara. semasa memberikan ucaptama di majlis perasmian seminar 'A Practical Approach to Criminal Procedure' di Pusat Dagangan Dunia Putra pada 15 Oktober, 2002. 
I might add that fairness is not a concept invented in Strasbourg. Our laws, based on the common law, through the concept of abuse of process, has long sought to bring into effect the right to a fair procedure and fair trial. Obviously, if the affront to fair play and decency is disproportionate to society's interest in the effective prosecution of criminal cases, then the administration of justice is flawed. We should learn the lesson of history, ancient and modern, that a system of criminal law enforcement which comes to depend on shortcuts or which displays a profound lack of fairness of procedure will be less reliable and more subject to abuses than a system which depends on extrinsic evidence independently secured through skilful investigation. Whatever the future brings for the criminal law and procedure, our common law can lay claim to having a good record, for it does not lie supine in the face of apparent prejudice or unfairness. We try to come to terms with it and even if the reforms are nuanced, I am confident that changes are sought to make them better and that is indeed, an enormous tribute to the relevant agencies.

Justeru itu, sistem keadilan jenayah perlu dijalankan secara adil dan saksama. Perbicaraan yang adil hanya dapat dilakukan jika kedua-dua pihak yang terlibat berhujah dalam platform yang sama. Dalam erti kata yang lain, seseorang tertuduh harus diberikan ruang yang secukupnya untuk berhujah dan perkara ini hanya akan dapat dilakukan jika beliau diwakili oleh seorang peguam.

Situasi semasa menunjukkan bahawa wujudnya ketidakseimbangan dalam usaha mendapatkan khidmat peguam atas beberapa alasan seperti kuasa, kedudukan kewangan, kekurangan maklumat dan juga taraf hidup. Kos guaman yang tinggi merupakan penghalang kepada proses mencapai keadilan dalam mana-mana sistem perundangan jenayah sekalipun..$^{22}$ Tertuduh perlu membayar kos yang tinggi untuk mendapatkan khidmat peguam yang benar-benar mahir dan jika kes

22 Ranjit Singh s/o Harbinder Singh “Malaysia’s Way Towards Acces to Justice. Do we reform or not?” $12^{\text {th }}$ Biennial Malaysian Law Conference , 10-12/12/2003 Nikko Hotel, Kuala Lumpur. 
mengambil masa yang terlalu lama untuk diselesaikan. Keadaan ini seolah-olah menunjukkan bahawa khidmat peguam hanya boleh dinikmati oleh golongan yang berada sahaja. Perkara ini pernah disuarakan oleh Datuk Seri Najib Razak ${ }^{23}$ semasa memberikan ucapan pada Majlis Makan Malam Tahunan Majlis Peguam Pahang, yang berbunyi: ${ }^{24}$

Profesion ini semakin kurang mulianya kerana mereka memanipulasikan undang-undang kepada mereka yang sanggup membayar lebih dan menjadikan profesion itu satu perniagaan yang memberikan pendapatan lumayan. Perkhidmatan kepada orang ramai menjadi faktor kedua, selain mengenakan bayaran yang tinggi dan akhirnya memberi imej negatif kepada profesion ini. Saya berpendapat, kita mesti kembali kepada budaya memberi perkhidmatan. Saya percaya peguam perlu muhasabah diri dan tidak terlalu memikirkan keuntungan, sebaliknya membantu golongan yang kurang bernasib baik. Ia bukan bermakna mereka perlu bertindak seperti pusat kebajikan tetapi lebih kepada memberi khidmat kepada masyarakat.

Suasana dan prosedur perbicaraan yang teknikal akan menambahkan lagi tekanan kepada seorang tertuduh yang mungkin tidak pernah menjejakkan kakinya di mahkamah. Adalah tidak mustahil seorang individu yang tidak bersalah dan tidak diwakili oleh peguam semasa perbicaraan boleh mengaku salah kepada kesalahan akibat tekanan dan kurangnya pengetahuan beliau tentang prosedur undang-undang yang sedang dihadapinya. Terdapat kajian yang menunjukkan bahawa peratus, tertuduh yang tidak diwakili peguam semasa perbicaraan mengaku salah di atas pertuduhan, adalah tinggi. ${ }^{25}$

Di Malaysia, seseorang tertuduh yang tidak berkemampuan boleh mendapatkan bantuan daripada Jabatan Bantuan Guaman, Majlis Peguam atau khidmat peguam yang diberikan oleh mahkamah sendiri. Bantuan ini adalah untuk mengelakkan daripada berlakunya

23 Beliau adalah Perdana Menteri Malaysia.

24 “Peguam jangan hanya fikir untung” Mingguan Malaysia, 1 Mac 2009.

25 Gurdial Singh Nijar, The Position of the Unrepresented Accused in the Subordinate Court, Fakulti Undang-Undang, Universiti Malaya, LLM (1978) di muka surat 42 hingga 52. 
keadaan yang mana seseorang tertuduh terpaksa menerima kesan negatif daripada pertuduhan yang dikenakan ke atasnya hanya kerana ketidakmampuannya untuk melantik seorang peguam. ${ }^{26}$

Namun begitu, wujud juga masalah di mana ramai yang tidak mengetahui wujudnya badan-badan ini. Perkara ini secara tidak langsung boleh membantutkan usaha badan-badan ini dalam membantu mereka yang tidak berkemampuan. Terdapat juga khidmat bantuan guaman yang diberikan oleh badan-badan ini yang terhad kepada sesuatu perkara sahaja seperti pembelaan bagi kes-kes jenayah kecil. Dalam hal ini, jika ada pihak yang dituduh di bawah kesalahan yang lebih serius maka beliau tidak layak mendapat bantuan daripada badan-badan ini. Jika perkara ini berlaku, maka objektif utama penubuhan badan-badan ini tidak akan dapat dicapai. Di samping itu, terdapat juga kesukaran dalam pelaksanaan bantuan guaman ini secara optimum kepada pihak yang layak disebabkan oleh masalah seperti kurang sumber kewangan, kurang pengetahuan tentang kewujudan bantuan guaman, kurang staf atau sukarelawan dan undang-undang yang rigid. ${ }^{27}$

\section{Jabatan Bantuan Guaman}

Jabatan Bantuan Guaman (selepas ini dirujuk sebagai JBG) sebelum ini dikenali sebagai Biro Bantuan Guaman adalah merupakan sebuah badan kerajaan. ${ }^{28}$ Fungsinya adalah untuk memberi nasihat guaman yang berkaitan dengan undang-undang kepada individu yang tidak berkemampuan. Di antara bidang kuasa JBG adalah seperti mengendalikan kes-kes syariah, kes-kes sivil, memberikan nasihat guaman dalam semua perkara mengenai undang-undang dan juga menjadi pengantara bagi kes syariah dan sivil. ${ }^{29}$ Bidang kuasa JBG dalam kes jenayah adalah terhad kepada pengendalian kes-kes mengenai pengakuan bersalah, jenayah yang melibatkan kanakkanak dan kes jenayah kecil. ${ }^{30}$

26 Henry Hodge, Legal Rights, Arrow Books (1974) di muka surat 28. Lihat juga Legal Aid Handbook, London : Sweet \& Maxwell, (1991) di muka surat 3.

27 'Seminar on Legal services for the rural poor and other disadvantaged groups' (11-16 January,1987) Jakarta, Organized by the International Commisssioner of Jurist.

28 Pertukaran nama ini adalah bermula dari tarikh 16 Januari 2010; http://www. bbg.gov.my/ - Dirujuk pada 19 Januari 2010.

29 http://www.bheuu.gov.my/bbg/perkhidmatan.shtml - Dirujuk pada 5 Ogos 2008.

30 Ibid. 
Individu yang layak untuk menerima bantuan JBG adalah tertakluk kepada dua kategori berikut: ${ }^{31}$

i. Kategori pertama - Bantuan Guaman Percuma

Pemohon memiliki sumber kewangan yang tidak melebihi dua puluh lima ribu ringgit setahun.

ii. Kategori kedua - Bantuan Guaman dengan Sumbangan

Pemohon yang memiliki sumber kewangan yang melebihi dua puluh lima ribu ringgit setahun tetapi tidak melebihi tiga puluh ribu ringgit setahun. Sekiranya pemohon layak diberi bantuan guaman di bawah kategori ini, pemohon dikehendaki membayar sejumlah RM300.00 sebagai sumbangan kepada Ketua Pengarah JBG.

Namun begitu, terdapat juga pengecualian khas kepada peruntukan ini. Sekiranya seseorang itu tidak layak untuk mendapat bantuan guaman sama ada di bawah kategori pertama mahupun kategori kedua, dia boleh memohon pengecualian khas untuk mendapatkan bantuan guaman dengan kelulusan khas Menteri. Permohonan hendaklah dibuat melalui Ketua Pengarah JBG.

Bantuan yang diberikan oleh JBG diperuntukkan oleh Akta Bantuan Guaman 1971.32 Terdapat persoalan tentang kecukupan peranan yang dimainkan oleh JBG dalam memberikan bantuan guaman kepada golongan yang tidak berkemampuan. Akta Bantuan Guaman 1971 hanya membenarkan JBG membantu individu yang mengaku salah dalam sesuatu pertuduhan, ${ }^{33}$ kes yang melibatkan kanak-kanak dan juga kes jenayah kecil. ${ }^{34}$ Persoalan seterusnya ialah apakah yang akan berlaku kepada tertuduh yang dituduh di dalam keskes yang lebih serius seperti kes yang membawa kepada hukuman mati atau penjara 20 tahun atau seumur hidup? Dalam hal ini, jelas menunjukkan bahawa JBG tidak boleh membantu golongan ini kecuali mereka yang ingin mengaku salah terhadap kesalahan tersebut. Namun begitu, kes-kes yang melibatkan pengakuan salah hanya untuk meringankan hukuman dan ia hanya memberikan kesan yang kecil ke atas hukuman tersebut. Terdapat juga kemungkinan

31 Ibid.

32 Akta 26.

33 Jadual 2 Akta Bantuan Guaman 1971.

34 Seksyen 10 Akta Bantuan Guaman 1971. 
berlakunya kes-kes yang mana seseorang tertuduh terpaksa memilih untuk membuat pengakuan bersalah semata-mata ingin mendapatkan bantuan JBG..$^{35}$ Jika perkara ini berlaku maka keadilan tidak akan dapat dicapai malah hanya akan memberikan ketidakadilan kepada pihak-pihak yang berkenaan.

Justeru itu, adalah perlu agar JBG ini memberikan peluang yang lebih banyak kepada pihak-pihak yang tidak berkemampuan untuk mendapatkan peguam atas alasan kemiskinan. Kerajaan harus menghapuskan stigma bahawa ia tidak perlu memberikan bantuan guaman kepada mereka yang dituduh di bawah suatu kesalahan jenayah. ${ }^{36}$ Ini kerana seseorang yang baru dituduh bagi sesuatu kesalahan jenayah berhak untuk dianggap tidak bersalah sebelum dibuktikan sebaliknya oleh mahkamah. ${ }^{37}$ Oleh yang demikian, perubahan ini adalah penting agar peranan JBG ini akan lebih sesuai dengan perkembangan semasa masyarakat masa kini. Perubahan ini juga perlu selari dengan objektif penubuhan JBG yang ingin membantu golongan yang tidak berkemampuan dalam mendapatkan bantuan guaman. ${ }^{38}$

Walau bagaimanapun, bantuan guaman masih boleh diberikan kepada tertuduh dalam kes-kes yang tidak dinyatakan di dalam Jadual 2 Akta Biro Bantuan Guaman 1971. ${ }^{39}$ Dalam hal ini, kebenaran bertulis boleh diberikan oleh Menteri kepada Ketua Pengarah JBG untuk membantu tertuduh dalam prosiding jenayah bagi tujuan keadilan. Walau bagaimanapun, peruntukan ini amat jarang digunakan.

Berdasarkan kepada data yang dikeluarkan oleh JBG pada tahun 2006, sejumlah 159 kes jenayah yang dikendalikan oleh pihak mereka melibatkan kes-kes pengakuan bersalah. ${ }^{40}$ Manakala kes yang melibatkan jenayah kanak-kanak hanya lima kes dan rayuan

35 G.S Nijar "Legal Profesion: Its Responsibility and Contribution to Society" INSAF, Special Edition (1991) di muka surat 129.

36 Param Cumaraswamy "Legal Profesion: Its Responsibility and Contribution to Society” INSAF, Special Edition (1991) di muka surat 117; Tun Mohd Suffian, "Some problems facing the administration of justice - as seen by a judge" Third Malaysian Law Conference, Kuala Lumpur, 13-15 Oktober 1975.

37 Laporan Suruhanjaya Hak Asasi Manusia 2008, di muka surat 9.

38 S Sothi Rachagan "The Role of Lawyers and The Bar Council in Society" [1995] 2 M.L.J. xxix.

39 Seksyen 10(2A) Akta Bantuan Guaman 1971.

40 http://www.bheuu.gov.my/bbg/perkhidmatan.shtml - Dirujuk pada 5 Ogos 2008. 
jenayah ialah tujuh kes pada tahun yang sama. ${ }^{41}$ Ia dapat dilihat daripada maklumat berkenaan jumlah kes yang telah dikendalikan oleh JBG dalam Jadual $2 .{ }^{42}$

Jadual 1

Kes-Kes Jenayah Yang Didaftarkan Di Jabatan Bantuan Guaman Mengikut Negeri Dari Bulan Januari Sehingga November 2008

\begin{tabular}{|c|c|}
\hline CAWANGAN & JUMLAH KES JENAYAH \\
\hline PERLIS & 112 \\
\hline KEDAH & 275 \\
\hline PULAU PINANG & 12 \\
\hline PERAK & 88 \\
\hline W.PERSEKUTUAN & 20 \\
\hline SELANGOR & 25 \\
\hline NEGERI SEMBILAN & 7 \\
\hline MELAKA & 64 \\
\hline JOHOR BHARU & 32 \\
\hline PAHANG & 55 \\
\hline TERENGGANU & 47 \\
\hline KELANTAN & 4 \\
\hline SERAWAK & 4 \\
\hline SABAH & 44 \\
\hline LANGKAWI & 4 \\
\hline TAIPING & 6 \\
\hline MUAR & 2 \\
\hline \multicolumn{2}{|l|}{ GUA MUSANG } \\
\hline RAUB & 2 \\
\hline MIRI & 4 \\
\hline \multicolumn{2}{|l|}{ SIBU } \\
\hline LABUAN & 5 \\
\hline PUTRAJAYA & 2 \\
\hline JUMLAH & 814 \\
\hline
\end{tabular}

Sumber: Jabatan Bantuan Guaman, Putrajaya

41 Ibid.

42 Maklumat ini diperolehi oleh penulis semasa membuat kajian di Jabatan Bantuan Guaman Putrajaya pada 3 Februari 2009. 
Jadual 2

Bilangan Kes Yang Didaftarkan Di Jabatan Bantuan Guaman Mengikut Kes Dari Tahun 2000 Sehingga Bulan November 2008

\begin{tabular}{|c|c|c|c|c|c|}
\hline TAHUN & $\begin{array}{c}\text { KES } \\
\text { SYARIAH }\end{array}$ & $\begin{array}{c}\text { KES SIVIL } \\
\text { KEKELUARGAAN }\end{array}$ & $\begin{array}{c}\text { KES SIVIL } \\
\text { PELBAGAI }\end{array}$ & $\begin{array}{c}\text { KES } \\
\text { JENAYAH }\end{array}$ & JUMLAH \\
\hline $\mathbf{2 0 0 0}$ & 5900 & 780 & 320 & 279 & 7279 \\
\hline $\mathbf{2 0 0 1}$ & 5980 & 980 & 405 & 359 & 7724 \\
\hline $\mathbf{2 0 0 2}$ & 6405 & 1073 & 403 & 355 & 8236 \\
\hline $\mathbf{2 0 0 3}$ & 6762 & 1194 & 367 & 443 & 8766 \\
\hline $\mathbf{2 0 0 4}$ & 5211 & 930 & 180 & 194 & 6515 \\
\hline $\mathbf{2 0 0 5}$ & 7056 & 1385 & 209 & 253 & 8903 \\
\hline $\mathbf{2 0 0 6}$ & 7347 & 1703 & 209 & 309 & 9568 \\
\hline $\mathbf{2 0 0 7}$ & 7914 & 1999 & 257 & 475 & 10645 \\
\hline $\begin{array}{c}\mathbf{2 0 0 8} \\
\text { (sehingga } \\
\text { bulan } \\
\text { November) }\end{array}$ & 7558 & 1900 & 194 & 814 & 10456 \\
\hline JUMLAH & $\mathbf{6 0 1 3 3}$ & $\mathbf{1 1 9 4 4}$ & $\mathbf{2 5 3 4}$ & $\mathbf{3 4 8 1}$ & $\mathbf{7 8 0 9 2}$ \\
\hline
\end{tabular}

Sumber: Jabatan Bantuan Guaman, Putrajaya

Berdasarkan kepada Jadual 2 di atas, jelas menunjukkan bahawa keskes jenayah yang dikendalikan oleh JBG pada tahun 2000 sehingga bulan November 2008 adalah yang paling rendah sekali. Malahan kes-kes syariah merupakan kes yang mendominasi jumlah kes yang dikendalikan oleh JBG. Jadual 1 menunjukkan jumlah kes yang kecil bagi kes-kes jenayah yang dikendalikan oleh JBG bagi seluruh cawangannya di Malaysia. Malah, terdapat sesetengah cawangan seperti Sibu dan Muar langsung tiada kes jenayah didaftarkan pada tahun tersebut. Wilayah Persekutuan pula hanya mencatatkan sejumlah 20 kes jenayah sahaja pada tahun 2008.

Ini jelas menunjukkan bahawa bilangan kes jenayah yang dikendalikan oleh JBG adalah kecil. Perkara ini mungkin disebabkan oleh fungsi JBG yang terhad dalam kes-kes jenayah. Malahan perkara ini mungkin juga disebabkan oleh promosi yang dijalankan oleh JBG tidak sampai ke golongan sasaran. Ini menyebabkan mereka tidak tahu kewujudan dan peranan yang dimainkan oleh badan ini. Justeru itu, penulis berpendapat bahawa JBG harus bertindak lebih 
agresif lagi dalam mempromosikan khidmatnya kepada masyarakat umum. Selain daripada itu, Akta Bantuan Guaman 1971 perlu dipinda untuk memperluaskan peranan JBG dalam kes jenayah.

\section{Mahkamah}

Mahkamah turut menyediakan bantuan guaman kepada seseorang tertuduh yang sedang dibicarakan tetapi tidak berkemampuan untuk mendapatkan khidmat tersebut. Bantuan guaman ini terhad kepada kes-kes yang membawa hukuman mati atau penjara seumur hidup sahaja. Dalam kes-kes sebegini, tertuduh akan diwakili oleh peguam berdasarkan kepada senarai peguam yang berdaftar dengan mahkamah. Para peguam yang dilantik akan dibayar oleh mahkamah. Mahkamah akan memantau peguam-peguam ini dan jika wujudnya aduan terhadap mereka, nama mereka akan dikeluarkan daripada senarai peguam yang berdaftar dengan mahkamah. Kebiasaannya, peguam yang ternama tidak berdaftar dengan mahkamah kerana mereka telah mempunyai kes yang banyak untuk dikendalikan. Bagi tertuduh pula, mereka tiada pilihan untuk memilih peguam mereka sendiri. Namun begitu, mereka boleh memohon untuk menukar peguam jika terbukti peguam yang mewakili mereka adalah berat sebelah atau tidak kompeten. Bantuan daripada mahkamah ini secara tidak langsung dapat membantu tertuduh dalam mengendalikan pembelaan mereka semasa perbicaraan.

\section{Majlis Peguam Malaysia}

Majlis Peguam Malaysia (selepas ini dirujuk sebagai MPM) turut memberikan khidmat guaman percuma kepada masyarakat yang kurang berkemampuan. Malahan skop bantuan yang diberikan oleh MPM ini adalah lebih luas jika dibandingkan dengan skop bantuan yang disediakan oleh JBG. MPM memberikan bantuan guaman dalam setiap jenis kesalahan jenayah kecuali kesalahan yang boleh membawa kepada hukuman mati. Di samping itu, bagi kes-kes sivil, MPM memberikan bantuan bagi semua jenis guaman sivil kecuali kes-kes berkenaan pemungutan hutang atau kes-kes berkenaan dengan tuntutan kemalangan bermotor. ${ }^{43}$ Perkara ini bertepatan dengan objektif penubuhan MPM iaitu untuk;

43 Teo Say Eng, Hak Anda dan Undang-Undang, Petaling Jaya : LexisNexis (2007) di muka surat 54. 
i. Memberikan khidmat percuma bagi nasihat guaman dan khidmat peguam bagi kes-kes sivil dan juga jenayah.

ii. Memberikan bantuan dalam mitigasi untuk hukuman, prosiding reman serta permohonan untuk jaminan.

iii. Mewujudkan kesedaran serta memberikan maklumat kepada masyarakat mengenai hak-hak mereka dari segi undangundang.

Bagi melayakkan seseorang individu mendapatkan bantuan daripada MPM, pendapatan mereka setelah ditolak dengan perbelanjaan bulanan haruslah tidak melebihi RM650.00 bagi yang bujang dan RM900.00 bagi yang sudah berumah tangga. Selain daripada itu, mereka juga tertakluk kepada syarat; tidak memiliki rumah yang melebihi nilai RM45,000.00; kereta yang tidak melebihi nilai RM10,000.00; motosikal yang tidak melebihi nilai RM4,500.00; dan simpanan yang tidak melebihi RM5000.00. Ini bermakna, individuindividu yang memiliki harta yang lebih rendah atau bersamaan nilai seperti yang disenaraikan boleh diberikan perkhidmatan peguam secara percuma. Perkhidmatan yang diberikan oleh MPM ini turut juga diberikan kepada warganegara asing.

Jumlah kes yang dikendalikan oleh MPMadalah memberangsangkan. Selain daripada individu yang datang sendiri ke MPM untuk mendapatkan bantuan, MPM juga menerima kes-kes yang dirujuk oleh Jabatan Bantuan Guaman. Walaupun peguam panel MPM melakukan tugas mereka secara sukarela, namun MPM membuat sedikit bayaran bagi meringankan tugas-tugas sukarelawan ini walaupun jumlah yang diberikan tidak seberapa. ${ }^{44}$ MPM turut memberikan khidmat peguam dalam kes-kes jenayah sehingga ke peringkat rayuan. ${ }^{45}$ MPM juga turut menjalankan program 'Dock Brief' yang disasarkan kepada tertuduh-tertuduh yang telah mengaku salah dan ingin merayu untuk meringankan hukuman mereka. Program ini juga turut dipanjangkan ke pihak penjara dengan kerjasama Jabatan Penjara Malaysia. Ia secara tidak langsung dapat memberikan khidmat kepada tahanan-tahanan yang direman di penjara yang mungkin tidak tahu perkhidmatan yang ditawarkan oleh MPM atau tidak berkesempatan untuk ke MPM bagi mendapatkan bantuan. Tindakan proaktif sebegini secara tidak

44 Ibid. Khidmat guaman ini memperolehi peruntukan melalui bayaran yuran tahunan peguam pada setiap tahun.

45 Ibid. 
langsung dapat membantu pihak-pihak yang tidak berkemampuan. Namun begitu, masalah seperti sumber kewangan yang terhad, kekurangan sukarelawan serta kes yang banyak turut memberi kesan kepada usaha MPM untuk membantu golongan yang tidak berkemampuan ini.

Kerajaan prihatin dengan usaha yang dilakukan oleh MPM dan telah bersetuju untuk menubuhkan Yayasan Bantuan Guaman Kebangsaan seperti yang dinyatakan dalam pembentangan Belanjawan 2012 baru-baru ini. Dalam pembentangan belanjawan tersebut, kerajaan telah mengakui kepentingan hak untuk mendapatkan peguam ini kepada seseorang tertuduh dengan menyediakan bantuan sebanyak RM15 juta. Di dalam pembentangan belanjawan tersebut YAB Perdana Menteri menyatakan:

Kerajaan komited untuk mempastikan bahawa tidak ada orang yang dituduh atas kesalahan jenayah ternafi haknya untuk diguami. Pada kala ini, dianggarkan 80 peratus Orang Kena Tuduh dalam kes jenayah yang tidak mempunyai peguam untuk membela mereka kerana tidak berkemampuan bagi membayar fi guaman yang tinggi. Untuk ini, Yayasan Bantuan Guaman Kebangsaan akan mempastikan setiap individu yang didakwa di mahkamah akan diberi bantuan guaman secara percuma. Bagi maksud tersebut, Kerajaan akan menambah 10 juta ringgit lagi kepada yayasan pada tahun hadapan membawa jumlah keseluruhan sebanyak 15 juta ringgit. ${ }^{46}$

Bantuan ini adalah sesuatu yang amat dialu-alukan. Persoalan yang mungkin timbul ialah bagaimanakah ia akan dilaksanakan? Adakah bantuan ini mencukupi memandangkan peningkatan keskes jenayah yang berlaku? Apakah yang akan berlaku apabila peruntukan ini habis digunakan nanti dan apabila keadaan ini berlaku adakah tertuduh perlu membayar sendiri yuran guaman ini walaupun tidak berkemampuan? Persoalan-persoalan inilah yang mungkin menjadi isu dalam usaha untuk membantu golongan yang tidak berkemampuan ini. Walau bagaimanapun, penubuhan Yayasan

46 http://www.pmo.gov.my/dokumenattached/speech/files/Belanjawan2012.pdfDirujuk pada 15 November, 2011. 
Bantuan Guaman Kebangsaan adalah suatu usaha yang murni kerana ia sememangnya akan dapat membantu seseorang tertuduh yang tidak berkemampuan semasa perbicaraan.

Perkara yang sama juga telah lama diamalkan oleh negera-negara lain seperti Afrika Selatan, India dan United Kingdom dalam menjamin konsep keadilan dalam sistem perundangan jenayah. Berbanding Malaysia, di negara-negara tersebut kerajaan mempunyai obligasi undang-undang untuk memberikan bantuan guaman kepada semua tertuduh yang tidak berkemampuan. Di Malaysia, bantuan yang disediakan oleh pihak kerajaan hanyalah berteraskan keprihatinan dan kesedaran bahawa adalah penting untuk menyediakan bantuan guaman kepada seseorang tertuduh yang tidak berkemampuan semasa perbicaraan. Oleh itu, adalah diharapkan agar bantuan dan penubuhan Yayasan Bantuan Guaman Kebangsaan akan dapat membantu golongan tertuduh yang tidak berkemampuan dalam mengecapi hak yang telah diperuntukan di bawah Artikel 5(3) serta jaminan kesamarataan dari segi undang-undang melalui Artikel 8(1) Perlembagaan Persekutuan. ${ }^{47}$

\section{Kedudukan di negara-negara lain}

Di Afrika Selatan, hak untuk mendapatkan bantuan guaman merupakan suatu hak yang telah dijamin oleh Perlembagaan. ${ }^{48}$ Di bawah Perlembagaan Afrika Selatan, seseorang tertuduh yang tidak berkemampuan berhak untuk diberi bantuan guaman yang akan dibiayai oleh pihak kerajaan. ${ }^{49}$ Ia adalah sebahagian daripada hak tertuduh untuk mendapatkan suatu perbicaraan yang adil dan saksama. ${ }^{50}$ Malahan hak untuk dimaklumkan mengenai bantuan guaman kepada tertuduh ini juga harus dibuat dengan segera. ${ }^{51}$ Di Afrika Selatan, Lembaga Bantuan Guaman ditubuhkan untuk memberikan bantuan kepada semua tertuduh yang tidak mampu untuk mendapatkan khidmat seorang peguam. ${ }^{52}$ Lembaga Bantuan

47 Hak untuk dibela ini juga diperuntukkan di bawah seksyen 255 Kanun Prosedur Jenayah.

48 Di Malaysia, Artikel 5(3) Perlembagaan Persekutuan hanya memperuntukkan hak untuk mendapatkan peguam kepada seseorang tertuduh tetapi bukan hak untuk mendapatkan bantuan guaman.

49 Seksyen 35(3)(g) Perlembagaan Afrika Selatan.

50 Ibid.

51 Ibid.

52 Ditubuhkan di bawah Legal Aid Act 22 of 1969. 
Guaman ini dibiayai oleh pihak kerajaan. ${ }^{53}$ Bantuan guaman yang diberikan merangkumi pelbagai jenis kesalahan jenayah seperti membunuh, merogol, merompak, mencuri dan juga bagi kesalahan rasuah. ${ }^{54}$ Selain daripada itu, bantuan guaman ini juga diberikan sehingga ke peringkat rayuan. Khidmat peguam tersebut dibayar oleh Lembaga Bantuan Guaman. ${ }^{55}$ Lembaga Bantuan Guaman tidak membenarkan seseorang tertuduh memilih peguamnya sendiri. ${ }^{56}$ Memandangkan hak untuk mendapatkan bantuan guaman merupakan hak yang telah dijamin oleh Perlembagaan Afrika Selatan, maka seseorang tertuduh yang tidak berkemampuan akan mendapat pembelaan yang sewajarnya. Malahan skop bantuan guaman yang diberikan pula adalah cukup luas.

Di India, hak seseorang tertuduh untuk mendapatkan bantuan guaman adalah merupakan hak yang telah diperuntukkan oleh Perlembagaan India. ${ }^{57}$ Hak ini adalah penting kerana ia berkait rapat dengan hak tertuduh untuk mendapatkan perbicaraan yang adil dan saksama. ${ }^{58}$ Justeru itu, adalah menjadi kewajipan hakim untuk memaklumkan kepada tertuduh bahawa beliau mempunyai hak untuk mendapatkan bantuan guaman secara percuma jika dia hadir ke mahkamah buat pertama kalinya tanpa peguam atas alasan kemiskinan. ${ }^{59}$ Kerajaan juga berkewajipan untuk memastikan bahawa tertuduh mendapat bantuan guaman secara percuma jika beliau tidak mampu untuk mendapatkannya atas alasan kemiskinan. ${ }^{60}$ Dalam keadaan ini, bantuan guaman boleh diberikan untuk membantu tertuduh yang tidak berkemampuan bagi semua jenis kes. Bagi melayakkan seseorang tertuduh mendapatkan bantuan ini, beliau hanya perlu membuktikan bahawa tuduhan yang dikenakan ke atasnya,

53 http://www.legal-aid.co.za/ - Dirujuk pada 25 Jun 2009.

54 “Legal Aid Guide 2009” (2009) @ Legal Aid Board South Africa, www.jutalaw. co.za - Dirujuk pada 15 Ogos 2008.

55 Ibid.

56 Op. cit. di muka surat 115 .

57 Artikel 39A Perlembagaan India berbunyi;

The State shall secure that the operation of the legal system promotes justice, on a basis of equal opportunity, and shall, in particular, provide free legal aid, by suitable legislation or schemes or in any other way, to ensure that opportunities for securing justice are not denied to any citizen by reason of economic or other disabilities.

58 D.J. De, The Constitution of India, Volume 1, Hyderabad : Asia Law House (2002) di muka surat 1254.

59 Ibid.

60 Kes Sheela v. State of Maharashtra, A.I.R. 1983 S.C. 378. 
jika disabitkan akan membawa hukuman penjara. ${ }^{61}$ Hak untuk mendapatkan bantuan guaman juga diberikan kepada seseorang tertuduh sehingga ke peringkat rayuan. ${ }^{62}$ Di India, kegagalan untuk memberikan bantuan guaman ini juga boleh menyebabkan suatu sabitan itu dibatalkan oleh mahkamah kecuali dapat dibuktikan bahawa tertuduh sendiri secara sukarela telah menolak hak ini. ${ }^{63}$ Hak untuk bantuan guaman ini juga telah diperuntukkan di bawah seksyen 304 Kanun Prosedur Jenayah India. ${ }^{64}$ Di bawah peruntukan ini, mahkamah harus memastikan bahawa seseorang tertuduh yang dibicarakan di hadapannya diwakili oleh seorang peguam. Jika tertuduh tidak berkemampuan untuk mendapatkan khidmat seorang peguam, maka mahkamah akan melantik peguam bagi pihaknya dan perbelanjaan pelantikan tersebut akan dibayar oleh kerajaan. ${ }^{65}$

Di United Kingdom pula, bantuan guaman dikawal selia oleh sebuah badan iaitu Legal Services Commission. ${ }^{66}$ Suruhanjaya ini dibiayai oleh Kementerian Kehakiman United Kingdom dan memberikan bantuan dalam semua bentuk kes kepada mereka yang tidak berkemampuan. Dalam perbicaraan jenayah juga, hak untuk mendapatkan bantuan guaman ini diberikan kepada semua kes tanpa sebarang sekatan dan perkara ini dinyatakan di bawah seksyen 3 Legal Aid and Asistance Act 1960 yang menyebut:

(1) Any person committed for trial for an indictable offence shall be entitled to free legal aid in the preparation and conduct of his defence at the trial, and shall be entitled to have counsel assigned to him for that purpose, if a certificate is granted in respect of that person under this section.

(2) A certificate may, subject to the provisions of subsection (3), be granted in respect of any person-

(a) by the committing justice, upon the person being committed for trial; or

61 D.J. De, The Constitution of India, Volume 1, Hyderabad : Asia Law House (2002) di muka surat 1255.

62 Op, cit. muka surat 1260.

63 Kes Suk Das v. Union Territory of Arunachal Pradesh [1986] 2 S.C.C. 401.

64 S.C. Sarkar, Sarkar on The Law of Criminal Procedure, $8^{\text {th }}$ Edition, New Delhi: India Law House (2002) di muka surat 994.

65 Seksyen 304(1) Kanun Prosedur Jenayah India; Kes Suk Das v. Union Territory, A [1986] S.C. 991; Kes Mool Chand v. State [1990] Cr. L.J. 682 Del.

66 Suruhanjaya ini ditubuhkan oleh Access to Justice Act 1999. 
(b) by the Chief Justice, at any time after reading the depositions (whether or not an application has previously been made to the committing justice).

(3) A certificate shall not be granted under this section in respect of any person unless it appears to the committing justice or the Chief Justice that his means are insufficient to enable him to obtain such aid.

Perkara yang sama juga diperuntukkan di bawah Seksyen 4 Legal Aid and Asistance Act 1960 yang antara lain menyatakan bahawa:

\begin{abstract}
Any person who appears or is brought before an examining justice or the magistrates' court charged with an indictable offence or an offence which is punishable, on summary conviction, with imprisonment, other than imprisonment in default only of payment of a fine, may apply to the justice or court, as the case may be, for free legal aid in the preparation and conduct of his defence before that justice or court, and, if on such application the justice or court is satisfied that the applicant has insufficient means to enable him to obtain legal aid for the purpose aforesaid, the justice or court shall grant in respect of the applicant a certificate which shall entitle him to have counsel assigned to him for that purpose.
\end{abstract}

Di United Kingdom, hak untuk mendapatkan bantuan guaman pada peringkat rayuan juga diberikan secara percuma ${ }^{67}$ Perkara ini secara tidak langsung telah membuka ruang yang seluas-luasnya untuk tertuduh mendapatkan bantuan guaman bagi semua kes jika beliau tidak berkemampuan. Perkara ini secara tidak langsung telah mewujudkan konsep keadilan di dalam sistem perundangan jenayah di negara tersebut. Selain daripada itu, kewujudan sistem bantuan guaman yang lebih luas dapat memastikan setiap individu yang dituduh akan terbela dan tiada seorang pun yang akan teraniaya dalam sesuatu perbicaraan jenayah tersebut.

67 Seksyen 3A dan seksyen 5 Legal Aid and Asistance Act 1960. 
Manakala di Amerika Syarikat pula, hak untuk mendapatkan peguam dijamin oleh Pindaan Keenam Perlembagaan Amerika Syarikat. ${ }^{68}$ Hak ini diberikan kepada tertuduh secara percuma jika tertuduh merupakan seorang yang tidak berkemampuan. ${ }^{69}$ Ini kerana, hak ini adalah salah satu elemen yang penting dalam menjalankan suatu perbicaraan yang adil dan saksama. ${ }^{70}$ Hak tertuduh untuk mendapatkan peguam bermula semenjak beliau ditangkap lagi dan pihak berkuasa harus memaklumkan dengan jelas kepada tertuduh mengenai hak ini sebelum sesi soal siasat bermula. ${ }^{71}$ Malahan hak ini juga diberikan kepada seseorang tertuduh sehingga ke peringkat rayuan. ${ }^{72}$ Selain itu, tertuduh yang menerima hak ini haruslah dibekalkan dengan seorang peguam yang kompeten bagi mengelakkan dirinya diprejudiskan semasa perbicaraan. ${ }^{73}$ Walau bagaimanapun, seseorang tertuduh boleh mengenepikan hak ini pada bila-bila masa secara sukarela. Jika perkara ini berlaku, maka seseorang tertuduh itu akan dibenarkan untuk membela dirinya sendiri tanpa bantuan daripada seorang peguam. ${ }^{74}$

\section{Kesimpulan}

Sebagai kesimpulannya, amalan yang telah dilakukan oleh negaranegara seperti Afrika Selatan, India, Amerika Syarikat dan juga di United Kingdom berkenaan hak untuk mendapatkan peguam adalah amat baik. Ini kerana bantuan guaman telah diberikan secara percuma dan ia telah menjadi tanggung jawab kerajaan untuk

68 Pindaan Keenam Perlembagaan Amerika Syarikat berbunyi;

An individual accused of a crime has the right to a speedy trial by an impartial jury, to be informed of the charges, to confront witnesses, and be assisted by legal counsel.

69 Gideon v. Wainwright, 372 U.S. 335 [1963].

70 Ibid.

71 Miranda v. Arizona, 384 U.S. 436 [1966]; Hak ini juga dikatakan wujud secara tidak langsung di dalam Pindaan Kelima Perlembagaan Amerika Syarikat yang berbunyi;

An individual charged with a crime is entitled to due legal process, cannot be tried twice for the same offense, and cannot be compelled to testify against him-or herself. The government cannot seize private property without just compensation.

72 Dougles v. California, 372 U.S. 353 [1963].

73 Mcmann v. Richardson, 387 U.S. 799 [1970]; Hall v. Lockhart, 474 U.S. 52 [1986].

74 Faretta v. California, 422 U.S. 806 [1975]. 
menyediakan kemudahan tersebut. Malahan, mahkamah di negaranegara berkenaan juga peka kepada hak tertuduh untuk dibela melalui seorang peguam dalam satu-satu kes jenayah. Perkara ini secara tidak langsung dapat menjamin sesuatu perbicaraan jenayah tersebut dapat dijalankan secara adil dan saksama. ${ }^{75} \mathrm{Hal}$ ini adalah berbeza dengan keadaan di Malaysia yang mana Jabatan Bantuan Guaman hanya mengendalikan kes-kes yang mana seseorang tertuduh telah mengaku salah sahaja. Manakala bantuan guaman yang dikendalikan oleh Majlis Peguam pula adalah terhad kerana kekurangan sumber dan sukarelawan. ${ }^{76}$ Malahan bantuan guaman yang dikendalikan oleh mahkamah juga adalah terhad pemakaiannya. Selain daripada itu, terdapat laporan yang menunjukkan bahawa wujud lebih kurang lapan puluh lima peratus tertuduh yang dituduh bagi kesalahan kecil di mahkamah tidak diwakili oleh peguam. ${ }^{77}$ Justeru itu, suatu perubahan perlu dilakukan di Malaysia bagi membolehkan bantuan guaman ini dilaksanakan secara lebih meluas. Ini bagi membolehkan golongan yang tidak berkemampuan untuk turut sama menikmati kemudahan tersebut selain dapat menjamin sesuatu perbicaraan itu dapat dilaksanakan secara adil dan saksama. Perubahan ini adalah amat penting dan harus disegerakan agar tiada pihak yang akan teraniaya oleh sebab kemiskinan yang tidak memungkinkan mereka untuk mendapatkan pembelaan daripada seorang peguam yang kompeten.

Dengan bantuan sebanyak RM15 juta seperti yang diperuntukan dalam belanjawan 2012 serta penubuhan Yayasan Bantuan Guaman Kebangsaan, perubahan diharap dapat dilakukan. Ini kerana, bantuan kepada golongan yang tidak berkemampuan dalam mendapatkan suatu perbicaraan yang adil adalah amat penting. Ia bukan sahaja merupakan hak asasi mereka malah ia juga adalah selari dengan prinsip asas undang-undang jenayah iaitu seseorang itu adalah tidak bersalah kecuali dibuktikan bersalah. Bantuan ini juga diharapkan mampu untuk memberikan makna yang lebih berkesan kepada hak untuk mendapatkan peguam seperti yang telah dijamin oleh Artikel 5(3) Perlembagaan Persekutuan. Malah Artikel 8(1) Perlembagaan

75 Alpert, Geoffrey, P., Legal Rights of Prisoners, Lexington, Mass : Lexington Books (1978) di muka surat 1.

76 Ibid.

77 “Najib setuju tubuh Yayasan Bantuan Guaman: Nazri” Mingguan Malaysia, 24 Januari 2010. 
Persekutuan juga memperuntukkan bahawa setiap individu adalah sama rata dan berhak mendapat perlindungan yang saksama dari segi undang-undang. Justeru itu, hak untuk mendapat peguam bagi golongan yang tidak berkemampuan ini harus dilaksanakan secara menyeluruh agar ia dapat dikecapi oleh seluruh golongan masyarakat di negara ini. 